\title{
Study of the effect of dicumyl peroxide on morphological and physical properties of foam injection molded poly(lactic acid)/poly(butylene succinate) blends
}

\author{
J. F. Campuzano ${ }^{1,2 *}$, I. D. López ${ }^{1}$ \\ ${ }^{1}$ Institute for the Plastic and Rubber Research and Training (ICIPC), 49 st, 050022 Medellin, Colombia \\ ${ }^{2}$ EAFIT University, 49 st, 050022 Medellin, Colombia
}

Received 8 July 2019; accepted in revised form 9 December 2019

\begin{abstract}
Blends of poly(lactic acid) (PLA) with poly(butylene succinate) (PBS) were compounded in the presence of dicumyl peroxide (DCP) to improve the compatibility and foaming capabilities. PLA/PBS blends with a weight ratio of $40 / 60$ and DCP contents of $0,0.1,0.4$ and $1 \mathrm{wt} \%$ were analyzed. Blends and neat materials were foam injection molded using azodicarbonamide as a chemical foaming agent. The thermal and rheological behaviors of materials are discussed. The morphologies and mechanical responses of the foamed samples are compared and analyzed. The best blend results were obtained with $0.1 \mathrm{wt} \%$ of peroxide, reaching impact strength values similar to those of neat-foamed PBS and cell population densities higher than neat PLA. Peroxide contents higher than $0.4 \mathrm{wt} \%$ tend to decrease the performance of the blend due to excessive crosslinking.
\end{abstract}

Keywords: biopolymers, biocomposites, foam injection molding, PLA/PBS blends, dicumyl peroxide, compatibilizer

\section{Introduction}

In recent years, there is a global concern about the consumption, use, and eventual disposal of non-biodegradable materials, including plastics, due to the adverse effects on the environment. The degradation time of conventional polymers is usually too long, so they tend to accumulate in landfills and natural habitats, polluting and threatening the ecosystems of the affected places [1]. Furthermore, due to the awareness of fossil fuel overconsumption, it is critical to encourage the search for new ways of producing or replacing currently used materials and products [2]. As such, biodegradable polymers have made their way as an alternative to conventional polymers in general-purpose applications. However, their relatively high cost and different mechanical properties compared to certain commodity polymers, are limitations for their widespread use in some applications [3].

Two of the most commonly used biodegradable polymers in the industry are poly (lactic acid) (PLA) and poly(butylene succinate) (PBS). PLA is a compostable thermoplastic polyester obtained from renewable resources such as cornstarch and sugarcane [2]. It has been one of the most widely used and studied biopolymers because of its properties-cost ratio [4]. On the other hand, PBS is a synthetic biodegradable aliphatic polyester obtained from the polycondensation of 1,4-butanediol with succinic acid [2]. This material has attracted considerable attention because of its high flexibility, impact strength, thermal and chemical resistance as well as good processability. Yet, this material is still too expensive compared with other polymers, and it has low stiffness, which limits its use

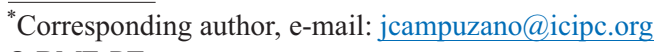

(C) BME-PT 
in high added value applications [5]. However, the high cost comes mainly from low worldwide production capacity, which is a variable that may improve over time [6].

With increasing global consumption of every product, particularly of plastics, the use of polymer foams has become an alternative of great interest. A foamed material allows reducing the weight of plastic products, enhancing its cost-benefit ratio. Foaming also tends to improve some product properties an characteristics like impact strength as well as thermal and acoustic insulation [7]. However, the drawback of other properties such as rigidity and resistance being affected should be considered in the application [8]. PLA foams have been analyzed as a potential replacement for expanded polystyrene (EPS) [9]. However, PLA has some limitations, such as its low melt strength, low toughness, low deflection temperature and high brittleness [10]. On the other hand, the implementation of PBS in the foam industry is limited due to its low molecular weight as well as its low melt strength and viscosity, which both reduce the foaming capabilities [11]. To overcome these limitations, this work proposes a material compound, in combination with the use of crosslinking agents as approaches that could improve these materials' foaming capabilities.

Conversely, polymer compounding represents an efficient and cost-effective way to improve the toughness of PLA, broadening its applications [12]. However, most of the polymer blends are not thermodynamically miscible as discussed by Muthuraj et al. [3] making the compounding and compatibilization of PLA, a subject of scientific interest. Several biopolymers are used to compound with PLA. Ren et al. [13] compounded PLA with poly(butylene adipate-coterephthalate) PBAT to produce binary and ternary blends with thermoplastic starch, obtaining compounds with enhanced toughness but using high percentages of PBAT. Nofar et al. [4] compounded PLA with PBAT to study the mechanical and bead foaming behaviors of the blends, reporting an increase in the strain at break of around $150 \%$ compared to neat PLA. Todo et al. [14] characterized the fracture mechanics of PLA and PCL compounds, obtaining good impact properties but low mechanical strength and low elongation at break. Arrieta et al. [15] blended PLA with poly(hydroxybutyrate) PHB, using natural terpene d-limonene (LIM) as a plasticizer, to obtain flexible films intended for food packaging applications with good thermal, barrier and mechanical properties. One of the most promising polymers to compound with PLA is PBS.

PLA/PBS blends have been widely studied due to their complementary characteristics, as low price and high stiffness of PLA contrasted with high toughness of PBS as reviewed by Nofar et al. [4]. In 2015, Deng et al. [5] studied the effects of PBS content from 0 to $90 \%$ on PLA/PBS blends on thermo-mechanical properties through phase morphology analysis. They found that Young's modulus and the tensile strength decrease as the concentration of PBS are increased. They disclosed the phase separation between both materials suggesting that the incorporation of a compatibilizer is required to improve the interfacial adhesion and miscibility of both phases. Although PLA/PBS miscibility has not yet been entirely cleared up, several research works have attempted to improve the materials' compatibility trough the incorporation of compatibilizers [16].

Dicumyl peroxide (DCP) has been used as an in situ compatibilizer and chain extender (CE) for biopolymers. As reviewed by Muthuraj et al. [3], DCP is an initiator to form crosslinked or branched structures by heterogeneous and homogeneous radical coupling reactions between both PLA and PBS polymers, producing small-sized inclusion phases and a good interfacial adhesion between the blend components. Ji et al. [17] reported a tensile strength decrease although with a significant increase of elongation at break in PLA/PBS blends when 0.2 and $0.3 \mathrm{wt} \%$ of peroxide were used. Wang et al. [18] also reported that the addition of DCP led to a reduction in the domain size of PBS phases as well as better interfacial adhesion between PLA and PBS when $0.1 \mathrm{wt} \%$ of peroxide was added in blends with $20 \mathrm{wt} \%$ PBS. The impact strength was also significantly increased. Ji et al. [17] reported that in blends with $20 \mathrm{wt} \%$ PBS, the addition of $0.3 \mathrm{wt} \%$ DCP increased the elongation at break from 49 to $205 \%$ and the tensile strength from 55 to $80 \mathrm{MPa}$.

Chain extenders (CE) have also been used to improve PLA and PBS foaming capabilities. Ludwiczak et al. [19] used the epoxide-based chain extender Joncryl in contents from 0.2 to $1.5 \mathrm{wt} \%$ for the chemical foaming of PLA. In the study, a fine cellular structure was obtained with a low density $\left(0.7 \mathrm{~g} / \mathrm{cm}^{3}\right)$. When $1.5 \mathrm{wt} \%$ of CE and 1\% CFA were used, the CE significantly influenced the cell structure by increasing the number of small cells. Bocz et al. [20] 
also used Joncryl to analyze the foaming of natural fiber reinforced PLA prepared by supercritical $\mathrm{CO}_{2}$ assisted extrusion. They found that the combined application of chain extender and talc effectively promoted the formation of uniform cell structures. Göttermann et al. [21] studied the effect of different chemical modifiers like Joncryl, DCP, styrene-maleic anhydride, among others, on the thermal and rheological properties of PLA for extrusion foaming. They found that the best modifier to enhance melt crystallization rate and melt strength was DCP. Standau et al. [22], investigated the effect of DCP on the rheological properties and its effect on the expansion behavior and foam properties of PLA extruded foams. They found that modified PLA foam compared to neat PLA foam reached twice the compression strength with a reduction of $30 \%$ in its density when $0.2 \mathrm{wt} \%$ of peroxide was used. Furthermore, the effect of DCP on the morphological and physical properties of PBS foams was analyzed by Boonprasertpoh et al. [11] and Feng et al. [23]. Both works evidence increases on the material viscosity, melt strength, and mechanical properties such as tensile strength when DCP was used.

In the state of the art, there are no relevant works about foaming PLA/PBS blends and how this can be improved using DCP as compatibilizer. The objective of this paper is to analyze for the first time the effect of DCP on foam injection molded PLA/PBS blends with chemical foaming agents (CFA) in order to overcome the limitations of the neat materials. In this work, the mechanical and morphological properties of PLA/PBS/DCP blends are investigated to have a better understanding of how the presence of DCP affect the foaming capabilities and performance of the modified blends.

\section{Experimental setup}

For the analysis, neat PLA and PBS were preconditioned for compounding in a twin-screw extruder both with and without compatibilizer. Then, the obtained blends were again preconditioned under the same conditions together with additional neat materials, later were dry mixed with a chemical foaming agent for foam injection molding to analyze the foaming capabilities and properties of each material. Finally, test samples were cut and characterized. Processing conditions for compounding and injection foaming were fixed to avoid possible changes in blends properties and performance related to processing parameters.
Below, all the materials, equipment and processes used are presented.

\subsection{Materials}

For the experimental setup, two biopolymers, one peroxide, and one chemical blowing agent were used. PLA 4043D was obtained from Nature Works LLC., USA, with a melt-flow index of $6.15 \mathrm{~g} / 10 \mathrm{~min}$ (at $210^{\circ} \mathrm{C}$ and $2.16 \mathrm{~kg}$ ) and a solid density of $1.24 \mathrm{~g} / \mathrm{cm}^{3}$. The second one, PBS FZ91, was acquired from PTT MCC Biochem Co., Ltd., Thailand, with a melt-flow index of $9.46 \mathrm{~g} / 10 \mathrm{~min}\left(\right.$ at $190^{\circ} \mathrm{C}$ and $2.16 \mathrm{~kg}$ ) and a solid density of $1.26 \mathrm{~g} / \mathrm{cm}^{3}$. A commercial dicumyl peroxide (DCP) with $98 \mathrm{wt} \%$ purity was used as compatibilizer and crosslinker in the blends.

An exothermic chemical foaming agent (CFA) was provided by Arcolor S.A, Arcoplast, Colombia, PE 2589 masterbatch with a $25 \mathrm{wt} \%$ content of azodicarbonamide in a carrier of PE. The CFA has a processing temperature of $210^{\circ} \mathrm{C}$. This agent was selected because it has been previously tested by other researchers in other biopolymer formulations [11, 24]. CFAs with biodegradable carriers are not commercially available. Therefore, CFA masterbatches with PE carriers were used. However, the low CFA contents required for foaming should not compromise the biodegradability, processability and performance of the blends.

\subsection{Compound preparation}

PLA and PBS were dried in a vacuum oven Vacutherm VT 6130 from Heraeus Instruments, Germany. A temperature of $80^{\circ} \mathrm{C}$ and a vacuum pressure of 200 mbar for 8 hours were used in order to avoid hydrolysis degradation during processing.

The PLA/PBS wt $\%$ ratio was set at $40 / 60$ with fixed DCP contents of $0,0.1,0.4$ and $1 \mathrm{wt} \%$. These ratios and contents were defined as a result from previous works performed at the ICIPC with PLA/PBS/DCP blends analysis for other applications and as a conclusion from results disclosed in the literature $[4,5]$, where higher PBS contents in the blends showed better mechanical and rheological properties. Regarding the DCP content, the best results reported in the literature are usually obtained in the range of 0.1 to $1 \mathrm{wt} \%$. Table 1 summarizes the blend code names and compositions [17, 18].

For the compounding process, a twin-screw extruder Micro 27 from Leistritz, Germany with $27 \mathrm{~mm}$ screw diameter, $44 L / D$, and sequential feeding. The screw 


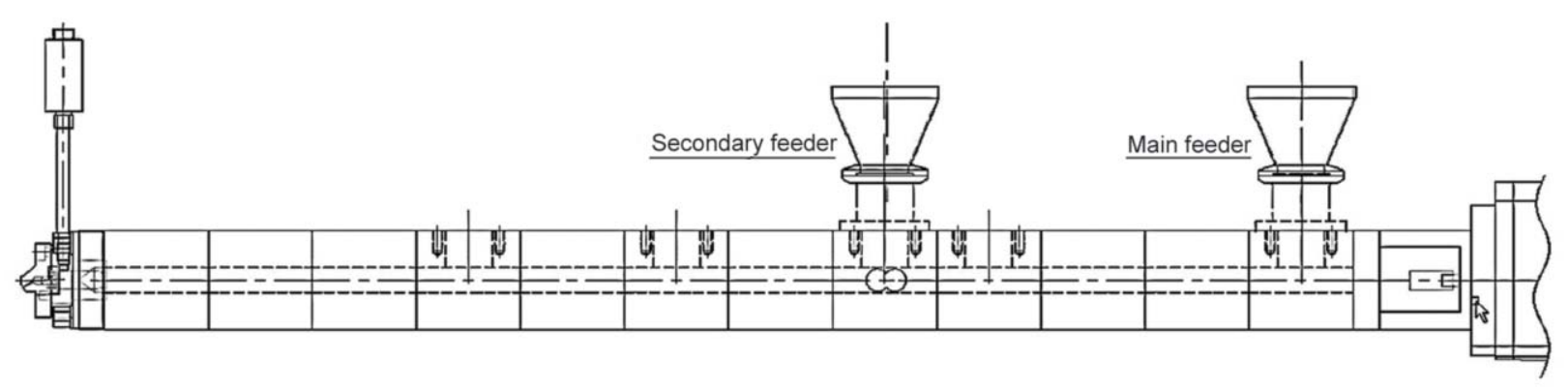

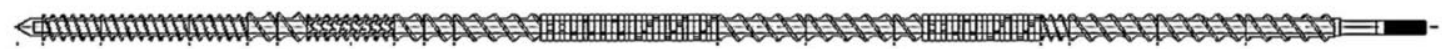

Figure 1. Screw and extruder configuration.

Table 1. Blends compositions.

\begin{tabular}{|l|c|c|c|}
\hline \multicolumn{1}{|c|}{ Blend } & $\begin{array}{c}\text { PLA } \\
{[\%]}\end{array}$ & $\begin{array}{c}\text { PBS } \\
{[\%]}\end{array}$ & $\begin{array}{c}\text { DCP } \\
{[\%]}\end{array}$ \\
\hline PLA & 100 & 0 & 0 \\
\hline PBS & 0 & 100 & 0 \\
\hline 0 DCP & 40 & 60 & 0 \\
\hline $0.1 \mathrm{DCP}$ & 40 & 60 & 0.1 \\
\hline $0.4 \mathrm{DCP}$ & 40 & 60 & 0.4 \\
\hline 1DCP & 40 & 60 & 1 \\
\hline
\end{tabular}

and extruder configurations are presented in Figure 1.

The extrusion process parameters were set as follows: screw speed of $110 \mathrm{rpm}$, an increasing temperature profile from $170^{\circ} \mathrm{C}$ at the feeding zone to $200^{\circ} \mathrm{C}$ at the die with a flow rate of $5 \mathrm{~kg} / \mathrm{h}$. As presented in Figure 1, two volumetric feeders where used. The main feeder was used for the PLA/PBS blends and the secondary feeder was used for the DCP powder to integrate the peroxide with the premixed melt.

\subsection{Samples foaming}

Test samples were injection molded on a conventional injection molding machine Allrounder 420CG of $\varnothing 35 \mathrm{~mm}$ screw diameter and $100 \mathrm{kN}$ clamping force from Arburg, Germany, with a two disk-shaped mold of $6 \mathrm{~mm}$ of thickness and a diameter of $\varnothing 85 \mathrm{~mm}$; all as presented in Figure 2. For sample preparation, the pelletized blends were dried under the same conditions mentioned earlier, and then they were dry mixed with CFA at $3 \mathrm{wt} \%$ before the injection molding process.

The injection process parameters were set for foamed samples as presented in Table 2.

The same shot volume was defined for all samples. The cavity was partially filled during the injection phase, and no packing pressure was applied to allow part foaming inside the cavity. The cooling time was

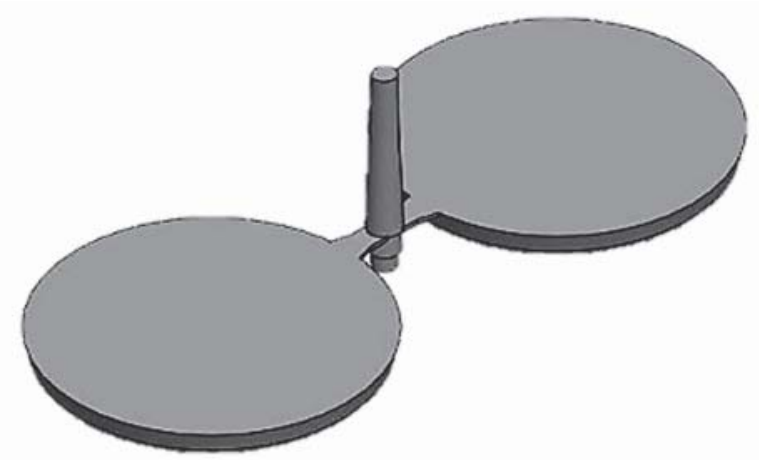

Figure 2. Injection molded discs.

Table 2. Injection molding process parameters.

\begin{tabular}{|ll|c|}
\hline & & Foamed samples \\
\hline Melt temperature & {$\left[{ }^{\circ} \mathrm{C}\right]$} & 210 \\
\hline Shot volume & {$\left[\mathrm{cm}^{3}\right]$} & 60 \\
\hline Injection flow rate & {$\left[\mathrm{cm}^{3} / \mathrm{s}\right]$} & 38 \\
\hline Packing pressure & {$[\mathrm{bar}]$} & - \\
\hline Packing time & {$[\mathrm{s}]$} & - \\
\hline Cooling time & {$[\mathrm{s}]$} & 100 \\
\hline Wall temperature & {$\left[{ }^{\circ} \mathrm{C}\right]$} & 40 \\
\hline
\end{tabular}

adjusted long enough to avoid part swelling during the ejection. Furthermore, the melt temperature was defined based on the decomposition temperature of the CFA and the processing temperature of the blends obtained by DSC measurements.

\subsection{Characterization}

For characterization, rectangular specimens from the disk samples were extracted according to Figure 3, with a thickness of $6 \mathrm{~mm}$, a width of $10 \mathrm{~mm}$ and a length of $85 \mathrm{~mm}$. Before the mechanical test, all samples were preconditioned at a temperature of $23.4^{\circ} \mathrm{C}$ with a relative humidity of $46 \%$ for 24 hours. Four samples were tested for each blend and the averages and the standard deviations of the results were reported.

The density of each sample was calculated by measuring the sample weight in an analytical bb1300 


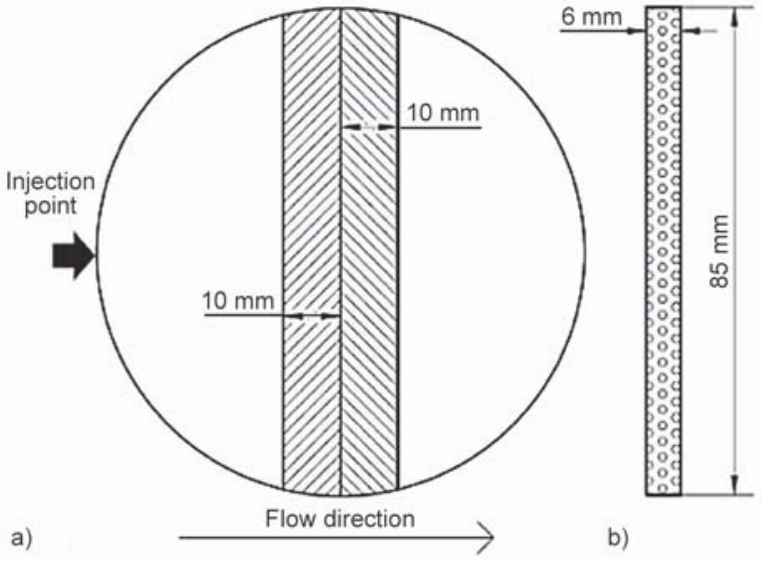

Figure 3. Scheme of the samples cut for characterization, a) disk front view, b) cross-section.

from Mettler Toledo, US and dividing by the known sample volume. Twelve samples were measured, and the average values were taken for each blend.

\subsubsection{Differential scanning calorimetry (DSC)}

Thermal transitions were measured on a DSC Q200 from TA Instruments, the US by Differential Scanning Calorimetry. The following procedure was performed to erase the thermal history and obtain the transition temperatures of the blends: $9 \mathrm{mg}$ of each material was heated from 30 to $220^{\circ} \mathrm{C}$ at a heating rate of $10 \mathrm{C} / \mathrm{min}$, using a nitrogen atmosphere $(50 \mathrm{ml} / \mathrm{min})$. Then, it was cooled down to $-30{ }^{\circ} \mathrm{C}$ at a cooling rate of $10^{\circ} \mathrm{C} / \mathrm{min}$, using the same atmosphere. Finally, the samples were heated again under the same conditions. The melting temperatures $\left(T_{\mathrm{m}}\right)$ and glass transition temperatures $\left(T_{\mathrm{g}}\right)$ of all the blends were reported.

\subsubsection{Thermogravimetric analysis (TGA)}

TGA measurements were performed with a TGA Q500 from TA Instruments, US under ASTM E1131 to verify the degradation temperature and composition of the CFA. For the test, a sample of $15 \mathrm{mg}$ of was heated at a heating rate of $10^{\circ} \mathrm{C} / \mathrm{min}$ from 20 to $900^{\circ} \mathrm{C}$, using a nitrogen atmosphere $(50 \mathrm{ml} / \mathrm{min})$ from 20 to $600^{\circ} \mathrm{C}$ and an oxygen atmosphere $(50 \mathrm{ml} / \mathrm{min})$ from 600 to $900^{\circ} \mathrm{C}$.

\subsubsection{Foam morphology characterization Micrographs}

The cell morphology of foamed samples was studied using a stereo microscope M420 from Leica, Germany. The samples were previously prepared using an electric polisher to obtain a mirror finish. Micrographs at $10 \times$ magnification were obtained and analyzed with the software ImageJ V1.52n. This information was used to characterize the samples according to the number of recorded cells, their size and distribution.

Furthermore, cell population density $(C p d)$ was calculated based on the Micrographs images, according to Equation (1) [24], where $n$ is the number of cells in the recorded image, $A\left[\mathrm{~cm}^{2}\right]$ is the cross-section area of the sample, $\rho_{\mathrm{s}}$ is the material's solid density and $\rho_{\mathrm{f}}$ the foamed density:

$\operatorname{Cpd}\left[\frac{\text { Cell }}{\mathrm{cm}^{3}}\right]=\left(\frac{n}{A}\right)^{3 / 2} \cdot \frac{\rho_{\mathrm{s}}}{\rho_{\mathrm{f}}}$

\subsubsection{Rheological properties}

The rheological properties of all blends were measured to analyze the complex viscosity and molecular weight variations. Tests were performed on a AR 2000 ex rotational rheometer from TA Instrument, the US on frequency sweep mode with a parallel plate of $\varnothing 25 \mathrm{~mm}$ and a gap of $1.6 \mathrm{~mm}$. Storage modulus $\left(G^{\prime}\right)$, loss modulus $\left(G^{\prime \prime}\right)$, and complex viscosity $\left(\eta^{*}\right)$ were measured as functions of frequency in the range from 600 to $1 \mathrm{rad} / \mathrm{s}$ at $200^{\circ} \mathrm{C}$.

\subsubsection{Mechanical characterization \\ Tensile strength}

Foam strength tests were performed with a universal testing machine 1455 Zwick/ Roell, Germany. Tensile strength tests were performed under ASTMD638. The test speed was $50 \mathrm{~mm} / \mathrm{min}$ with a grip to grip separation at the start position of $50 \mathrm{~mm}$ and $2 \mathrm{~N}$ of preload, and the tangent modules were taken between a strain of 0.05 and $0.25 \%$.

\section{Impact strength}

To analyze and compare the foamed samples toughness, notched impact strength tests were performed on a Hit 5.5P Zwick/ Roell, Germany, under ASTM D256-10 1EA. The weight used was $0.17 \mathrm{~kg}$ with an applied impact energy of $0.116 \pm 0.005 \mathrm{~J}$.

\section{Results and discussion}

\subsection{Thermal characterization}

DSC thermograms of the first cooling show the crystallization behavior of the blends. As shown in Figure $4 \mathrm{a}$, the temperature of the peak of crystallization 

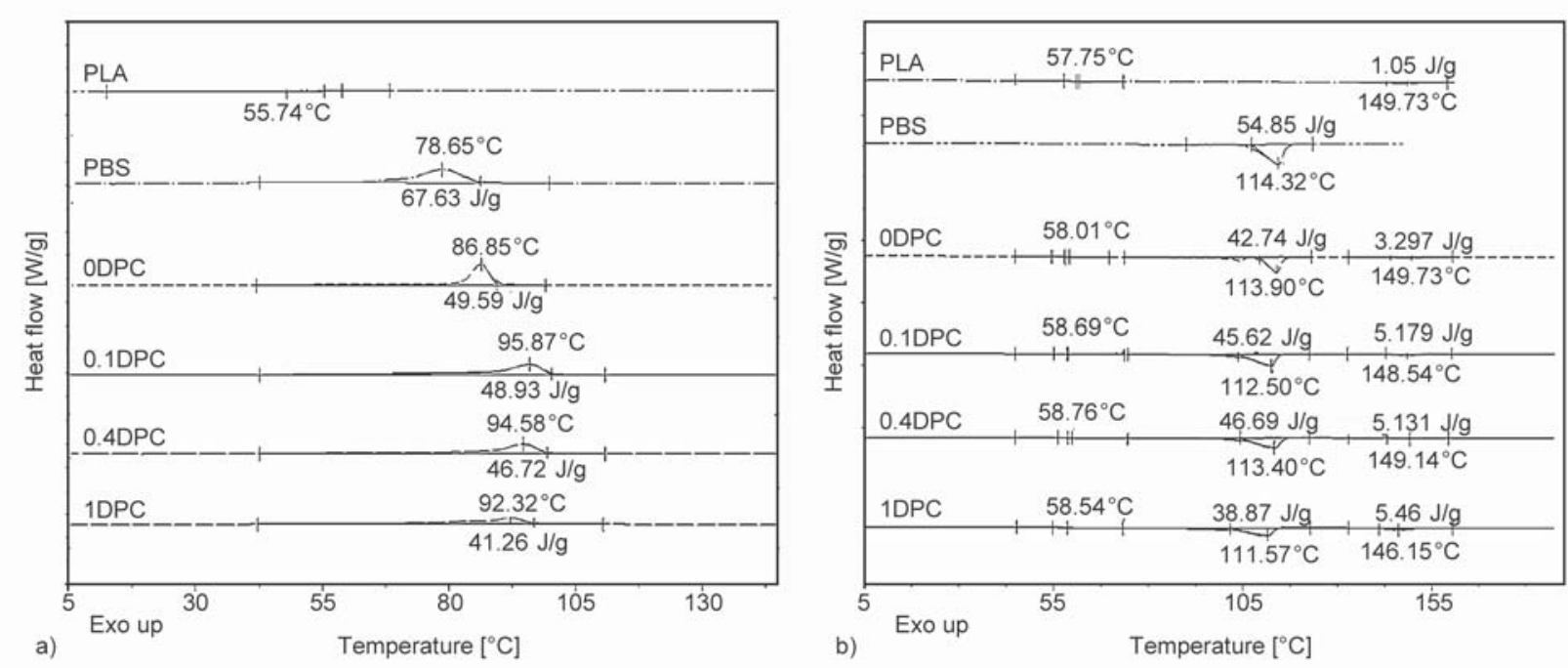

Figure 4. DSC of neat materials and blends. a) First cooling at a rate of $10^{\circ} \mathrm{C} / \mathrm{min}$, b) second heating at a rate of $10^{\circ} \mathrm{C} / \mathrm{min}$.

of PBS was increased with the presence of PLA in the blends (0DCP, 0.1DCP, 0.4CP, and 1DCP), where the immiscible characteristic of the two polymer phases PLA/PBS may facilitate the nucleation process. Furthermore, according to Nofar et al. [4], crosslinked structures affect crystallization. Without DCP (0DCP), the crystallization temperature of the PBS phase in the blend is $86.85^{\circ} \mathrm{C}$ and with $0.1 \%$ DCP this temperature increases $9.02^{\circ} \mathrm{C}$ and the onset crystallization temperature shifted to $100^{\circ} \mathrm{C}$. An increase of the crystallization temperature enhances cell stability during cooling, avoiding their collapse and obtaining a more stable structure.

The crystallization behavior can be tracked using the enthalpy values. The higher the enthalpy, the higher the crystallization degree. An increase of crystallinity of the PBS phase is obtained with the blend. Neat PBS reaches a crystallization enthalpy of 67.63 Joules per gram of PBS. Meanwhile, the blend 0DCP reaches 49.85 Joules per gram of blend. Since the blend has $60 \%$ of PBS, the adjusted crystallization enthalpy is 82.65 Joules per gram of PBS. The increase of peroxide reduces the molecular mobility, explaining the crystallization enthalpy reduction when $1 \%$ of DCP is used.

Figure $4 \mathrm{~b}$ shows the DSC curves of neat materials and blends. The glass transition temperature $\left(T_{\mathrm{g}}\right)$ of PLA is $58^{\circ} \mathrm{C}$ and the peak of melt temperature $\left(T_{\mathrm{m}}\right)$ is around $150^{\circ} \mathrm{C}$. For PBS, the melting peak is at $114^{\circ} \mathrm{C}$. Results show a slight increase in the glass temperature for the PLA phase related to the DCP content, and therefore to the reduction of the molecular mobility due to the crosslinking effect (from $57.75^{\circ} \mathrm{C}$ for neat PLA to $58.76^{\circ} \mathrm{C}$ for the blend with
$0.4 \%$ of DCP). Additionally, with the increase of DCP, the melting temperature peak tends to decrease, reinforcing that the molecular mobility is reduced due to the higher crosslinking degree of the blend.

The TGA curve of the CFA presented in Figure 5 shows three decomposition temperatures. The onset decomposition temperature is around $190^{\circ} \mathrm{C}$ and reaches its peak near $220^{\circ} \mathrm{C}$. According to ReyesLabarta [25], the first peak represents the primary decomposition of the azodicarbonamide where hydrazodicarbonamide, cyanic acid, and nitrogen gases are obtained. The peak of the decomposition temperature of PE is observed around $467^{\circ} \mathrm{C}$. The content of azodicarbonamide in the CFA masterbatch was confirmed $(25 \mathrm{wt} \%)$.

In chemical foaming, CFA should reach its decomposition temperature during the injection molding process, but the processing temperature should be as low as possible in order to increase the melt strength,

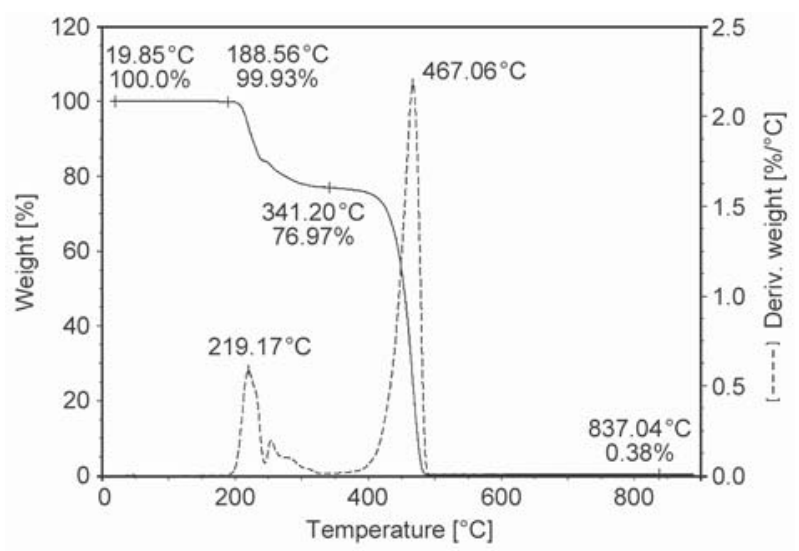

Figure 5. TGA of chemical foaming agent Arcoplast PE 2589. 
and therefore, the cell stability. For this reason, the recommended temperature process for foam injection molding should be around $210^{\circ} \mathrm{C}$. This value is approximately $60^{\circ} \mathrm{C}$ above the melt temperature of PLA, allowing an adequate gas generation and mix inside the polymer matrix.

\subsection{Rheological behavior}

High melt viscosity at low shear rates is characteristic of materials with adequate foaming capabilities because it is related to the material melt strength. This property is required to prevent cell collapse and obtain a good foam structure [26]. Figure 6 shows the frequency dependence of the blends' complex viscosity. According to the Cox-Merz rule [27], the complex viscosity is qualitatively related to the shear viscosity, and frequency is qualitatively related to the shear rate. Based on this rule, neat PLA shows a Newtonian behavior with frequencies below $10 \mathrm{rad} / \mathrm{s}$, while PBS and all the blends have a shear-thinning response in all the measured range. As expected, DCP increases viscosity. However, the shear-thinning behavior allows the blend processability at high shear rates, reaching viscosity close to those of the neat materials as was previously reported in other works [18]. The viscosity of blend 1DCP was not possible to measure due to the high crosslinking degree of the blend.

High molecular weight $\left(M_{\mathrm{w}}\right)$ is related to a high melt strength. The storage modulus $\left(G^{\prime}\right)$ is related to the elastic portion in the polymer [26]. From $G^{\prime}$ response (Figure 7), it can be concluded that the higher the DCP content, the higher $M_{\mathrm{w}}$, and hence, its melt strength. The lowest storage modulus was obtained for the PLA at low shear rates, but it equals the PBS

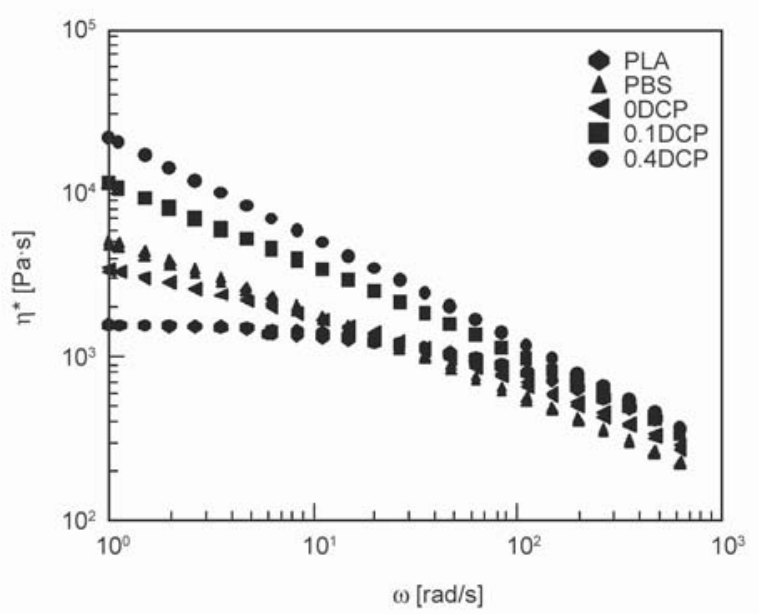

Figure 6. Frequency dependence of complex viscosity of PLA/PBS/DCP blends at $200{ }^{\circ} \mathrm{C}$.

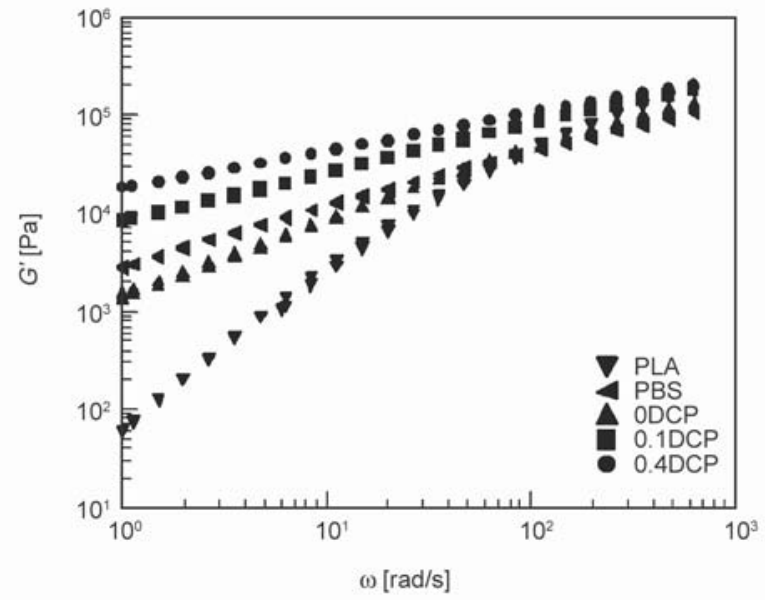

Figure 7. Storage modulus $G^{\prime}$ of PLA/PBS/DCP blends at $200^{\circ} \mathrm{C}$.

one at higher shear rates. The higher $G^{\prime}$ value is obtained when DCP is used, but there are no noteworthy changes when DCP content goes from 0.1 to $0.4 \mathrm{wt} \%$.

\subsection{Physical and morphological properties}

As expected from the rheological characterization, all the foamed blends but 1DCP were able to form well-shaped disc samples during the foam injection process. The value of $0.4 \mathrm{DCP}$ was selected since higher DCP concentrations make difficult the foam injection molding process. This result disagrees with the DCP contents used in some works, where amounts of peroxide higher than $3 \mathrm{wt} \%$ are reported for PLA and PBS foaming [23]. This difference may be explained by the usage of materials of lower molecular weight.

Since all samples were injection molded under the same processing conditions, the obtained results of foamed density and expansion ratio were similar, delivering values around $0.85 \pm 0.06$ and of $1.45 \pm 0.05 \mathrm{~g} / \mathrm{cm}^{3}$, respectively. Therefore, the obtained differences can be explained by the variability of the process and measurements and not by the composition of the blends.

\section{Micrographs}

Figure 8 shows the foamed structures of the neat polymer and blends after foaming. All samples exhibited close cell structures with two well-defined regions. The first region is a solid skin, which is the material that first touches the mold wall, cooling down without allowing the cells' formation and growth. This skin is usually found in any foamed injection molding part. The second region is the foamed core. The 
solid layer/part thickness ratio in foamed parts is ruled by the material thermal properties and processing parameters [20], and since the last ones were fixed, the difference can only be related to the foaming capabilities of the blends. The solid layer ratios were in the range from 17 to $28 \%$, where the highest ratio was obtained for neat PLA. This can be explained by the material melt temperature since the PLA temperature is $36^{\circ} \mathrm{C}$ higher than that of PBS (Figure 4). Therefore, PLA reaches its transition temperature faster than PBS during part cooling increasing the solid layer. The cell formation and growth in

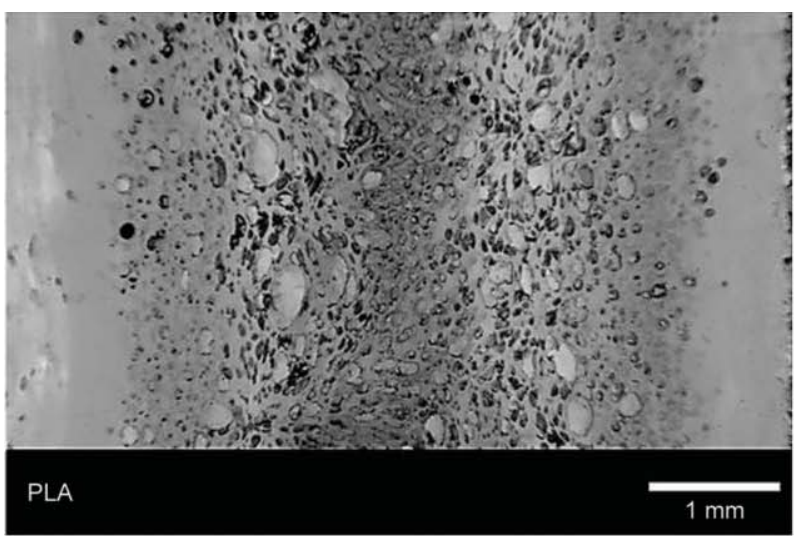

a)

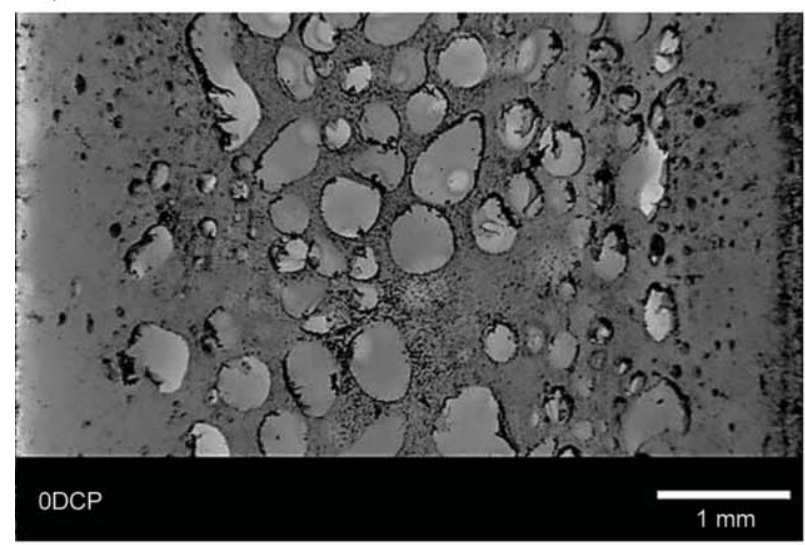

c)
PLA is limited to the part core, resulting in a large number of small cells in that region compared to the other materials. In all cases, the incorporation of PBS reduces the solid layer thickness because PBS has a lower melt temperature, which allows the cell formation during part cooling.

As can be seen in Figure 8, the shape of the cells in the PLA sample is slightly oval. Meanwhile, the morphology in the PBS and ODCP samples tends to be circular. On the other hand, in the samples with DCP (0.1DCP and 0.4DCP), the cells are oval and highly oriented in the flow direction. In these samples, the

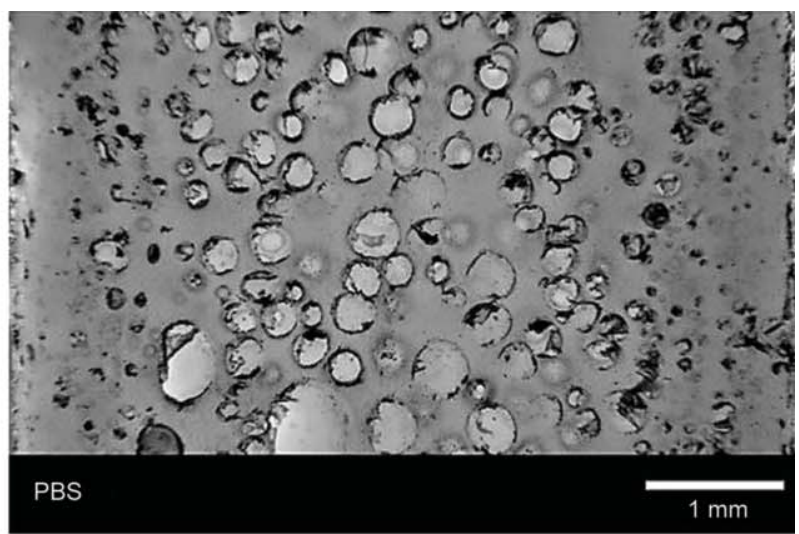

b)

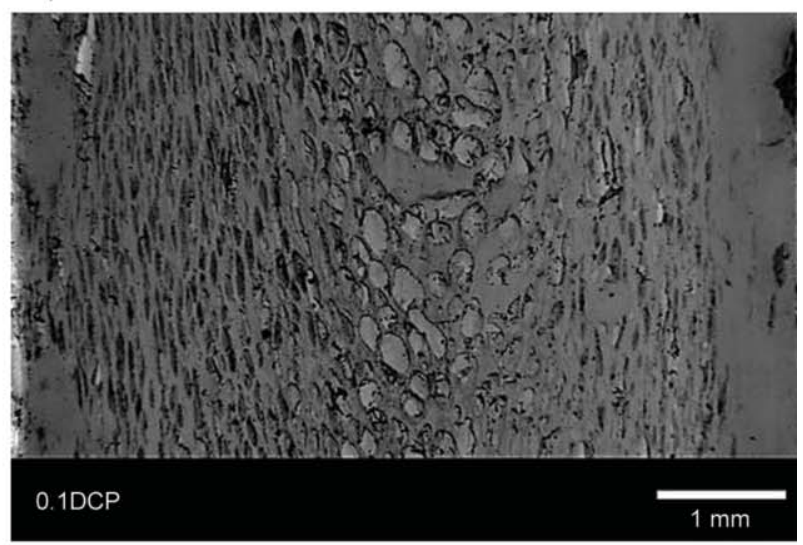

d)

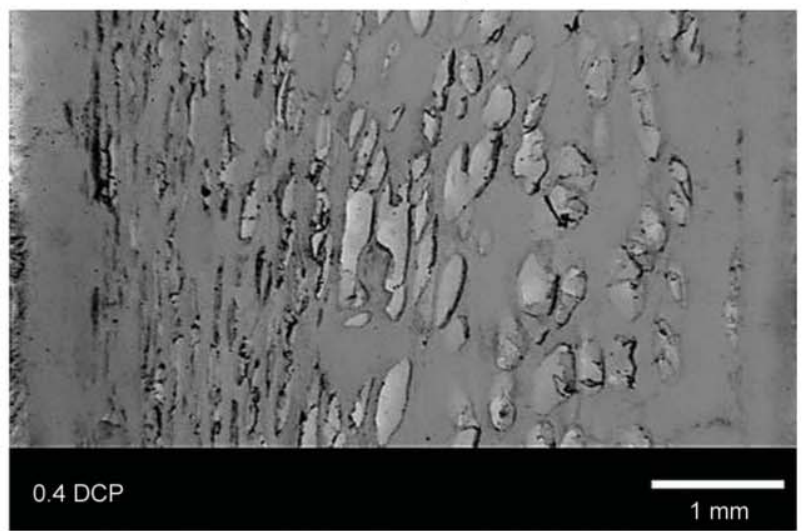

e)

Figure 8. Micrograph images of foamed neat materials and blends at $10 \times$ magnification. a) PLA b) PBS c) 0 DCP d) $0.1 D C P$ e) $0.4 \mathrm{DCP}$. 


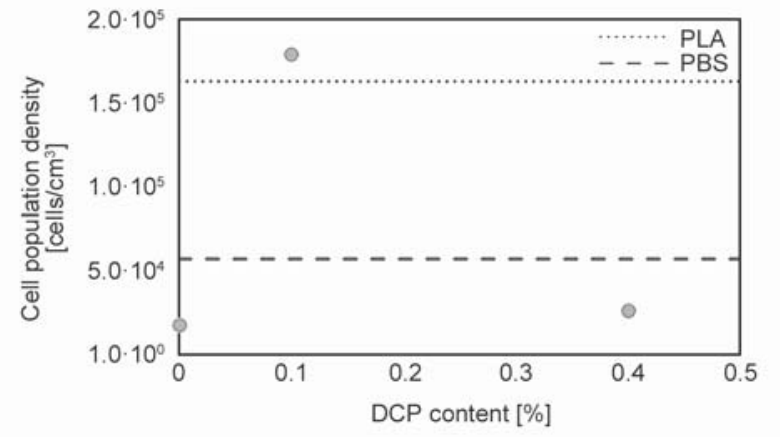

Figure 9. Cell population density of foamed samples.

orientation induced by the flow is frozen by the crosslinking process, obtaining and anisotropic structure. Meanwhile, in samples without DCP, the viscosity is lower, allowing that the cells that are formed during filling take a spherical shape during the cooling phase. Figure 9 presents the cell population density as a function of DCP content. The foamed neat PLA and neat PBS are presented as horizontal lines. The highest cell population densities and cell counts were obtained for PLA and 0.1DCP blend. In theory, the higher the cell population, the better the mechanical performance [28]. However, as will be discussed in the mechanical characterization, not only cell population is relevant but the material properties of the non-foamed blends.
The blend with $0.1 \%$ of peroxide offered a good compromise between the cell nucleation of the PLA with enhanced thermal behavior, allowing the cell formation and growth across the thickness. The blend without DCP showed lower cell population density. This is expected due to the low compatibility between PLA and PBS that affects cell structure stability. Blends with contents of DCP higher than $0.4 \%$ reduced the foaming capability due to the high crosslinking degree.

The cell size distributions of the samples were adjusted by a log-normal model. The results are presented in Figure 10, where 'Loc' represents the average of the natural logarithm of the cell size and 'Scale' its standard deviation, which is related to the width of the log-normal distribution. Neat PLA presents the smaller cell size with a 'Loc' of 4.312 (equivalent to $75 \mu \mathrm{m})$ and the narrowest distribution with a 'Scale' of 0.5983 , with $50 \%$ of cells in a range from 30 to $92 \mu \mathrm{m}$. PBS presented an equivalent average cell size of $125.1 \mu \mathrm{m}$ and a broader size distribution than PLA, having $50 \%$ of cells in a range of 27 to $149 \mu \mathrm{m}$ diameter. The highest 'Scale' values are obtained with 0DCP and 0.4DCP. This can be explained by the low compatibilities between the phases of the 0DCP blend and the high crosslinking of the $0.4 \mathrm{DCP}$ blend.

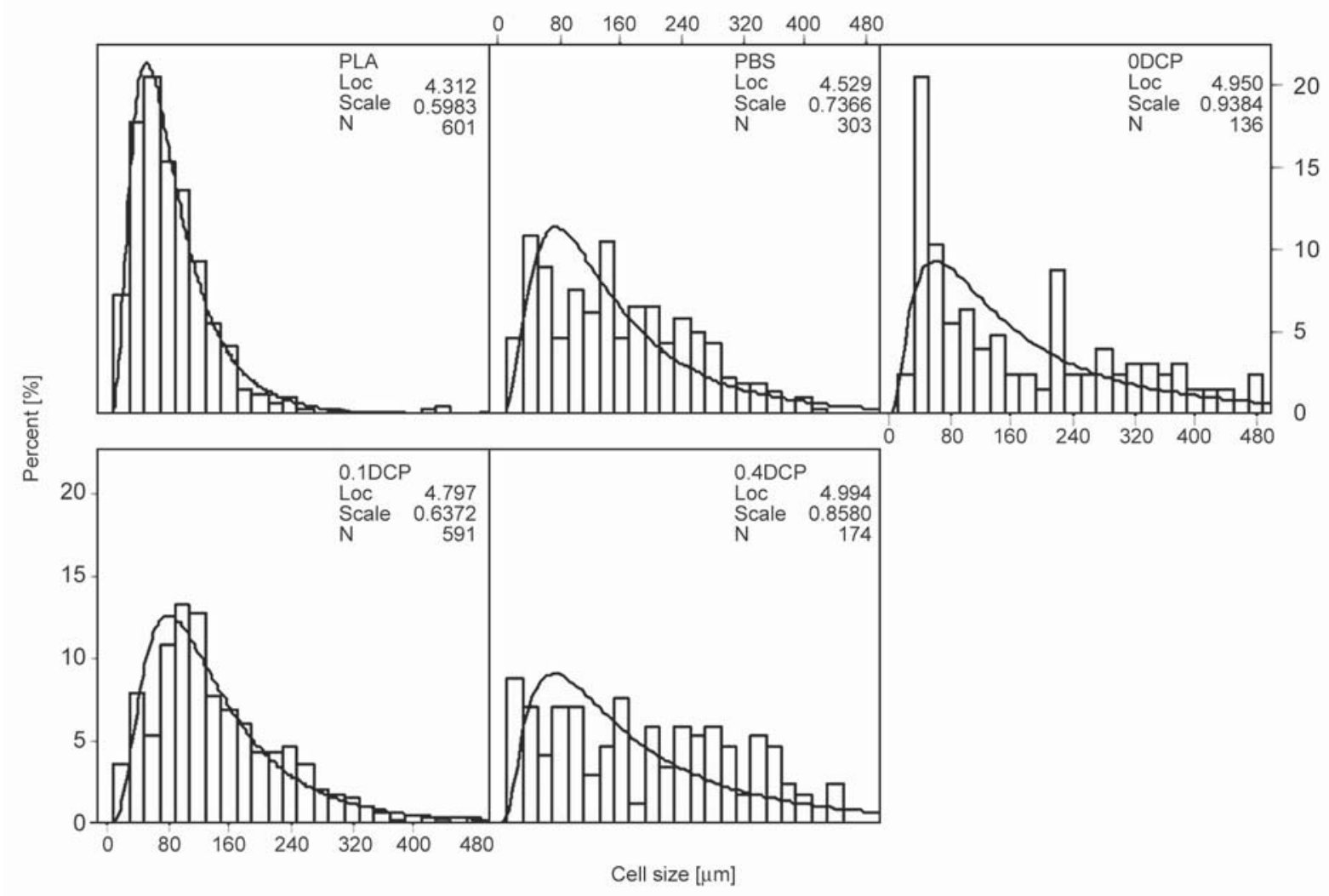

Figure 10. Cell morphology and size distribution. 
High 'Scale' values are not desired because this is a symptom of large cell presence, which may affect the mechanical properties. Finally, 0.1DCP offers better foaming structure morphology than the other blends, with an equivalent average cell size of $121.1 \mu \mathrm{m}$ and a narrow cell size distribution.

\subsection{Mechanical characterization}

The tensile and impact properties of blends are listed in Table 3. Results are presented as relative values dividing the material property by the foam density, e.g. yield strength/density (called relative yield strength). As stated before, the main goal of adding a ductile, flexible polymer like PBS to a rigid, brittle polymer such as PLA is to improve the toughness and reduce the rigidity of the PLA. In all cases, samples failed with a brittle fracture. As expected, the relatively highest Young modulus was obtained with PLA and the lowest value with PBS. All the blends reported similar modulus with a reduction of nearly 2.2 times the elastic modulus of neat PLA but around 1.5 times higher than PBS. In this property, the effect of the DCP content is negligible. The stiffness may be dominated by the solid skin of the samples; therefore, the effect of the foaming structure does not play a major role. Regarding the relative tensile strength, the best performance is obtained with PLA. The values of relative tensile strength for all the blends are slightly lower than PBS, obtaining the best performance with $0.1 \mathrm{DCP}$.

Regarding the elongation at break, the best performance was obtained with neat PBS and the lowest value with PLA. The major effect of the incompatibility of the materials was observed in this property, where the 0DCP blend reaches a similar deformation to PLA. By adding a low content of peroxide (0.1DCP), almost twice the elongation of the non-compatibilized blend is reached. However, the elongation drops again as the DCP content is increased. Peroxide is added in order to increase the compatibility of both phases; however, large quantities generate a highly

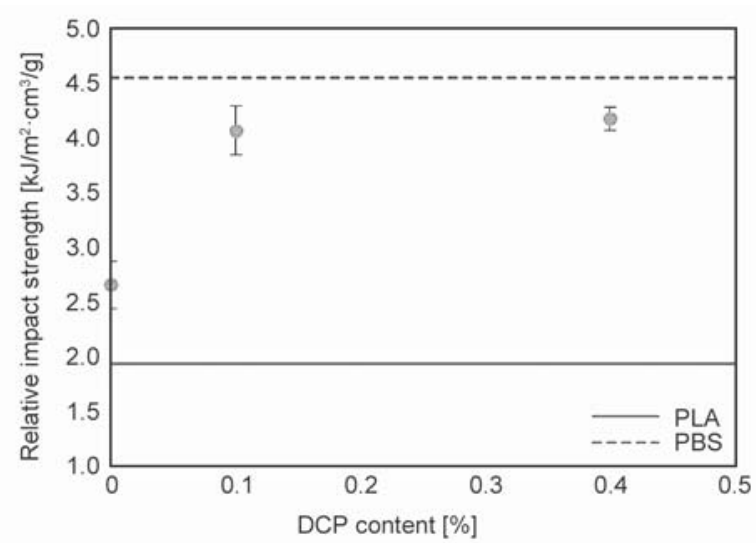

Figure 11. Relative notched impact strength for foamed samples.

crosslinked structure, affecting the ductility of the blends. The obtained elongation at break value for $0.1 \mathrm{DCP}$ approximately follows the mixing rule $(60 \%$ PBS, $40 \%$ PLA); therefore, a good balance of this property is obtained.

Figure 11 presents the relative notched impact strength as a function of the DCP content. Foamed PLA and PBS results are presented as horizontal lines. The best relative impact strength was obtained with PBS with almost 2.4 times the value of the PLA. By blending PLA and PBS without a compatibilizer (0DCP), the obtained impact strength is closer to PLA than PBS. However, by adding DCP, a stunning effect on impact strength is obtained, reaching almost the same strength of PBS. The results are similar for contents of $0.1 \%$ and $0.4 \%$ of DCP.

\section{Conclusions}

In this study, compounds of PBS and PLA were prepared using an industrial scale twin-screw extruder, where DCP was used as a compatibilizer and foamability enhancer of the blends. The neat materials and prepared blends were foam injection molded by chemical foaming in a conventional injection molding machine with azodicarbonamide as CFA. The mechanical properties and thermal behavior were studied in order to analyze the processability and

Table 3. Relative mechanical properties.

\begin{tabular}{|c|c|c|c|c|c|c|c|c|}
\hline Sample & $\begin{array}{c}\text { Relative Young } \\
\text { modulus } \\
{\left[\mathrm{MPa} \cdot \mathrm{cm}^{3} / \mathrm{g}\right]}\end{array}$ & $\begin{array}{l}\text { SD } \\
{[ \pm]}\end{array}$ & $\begin{array}{c}\text { Relative tensile } \\
\text { strength } \\
{\left[\mathrm{MPa} \cdot \mathrm{cm}^{3} / \mathrm{g}\right]}\end{array}$ & $\begin{array}{l}\text { SD } \\
{[ \pm]}\end{array}$ & $\begin{array}{c}\text { Elongation at } \\
\text { break } \\
{[\%]}\end{array}$ & $\begin{array}{l}\text { SD } \\
{[ \pm]}\end{array}$ & $\begin{array}{l}\text { Relative impact } \\
\text { strength } \\
{\left[\mathrm{kJ} / \mathrm{m}^{2} \cdot \mathrm{cm}^{3} / \mathrm{gr}\right]}\end{array}$ & $\begin{array}{l}\text { SD } \\
{[ \pm]}\end{array}$ \\
\hline PLA & 1637.41 & 77.15 & 24.71 & 0.98 & 3.15 & 0.52 & 1.94 & 0.21 \\
\hline PBS & 471.22 & 6.95 & 19.47 & 0.24 & 12.89 & 0.80 & 4.55 & 0.23 \\
\hline 0DCP & 747.80 & 45.48 & 16.52 & 0.38 & 3.87 & 0.47 & 2.65 & 0.10 \\
\hline $0.1 \mathrm{DCP}$ & 741.71 & 9.32 & 18.79 & 0.38 & 6.99 & 0.45 & 4.06 & 0.21 \\
\hline $0.4 \mathrm{DCP}$ & 778.73 & 38.22 & 15.11 & 0.53 & 3.84 & 0.24 & 4.17 & 0.19 \\
\hline
\end{tabular}


performance of each blend, compared to the neat materials. Also, the morphology of the obtained foamed structures was analyzed and discussed. The blend of PLA with PBS was studied because of their complementary properties.

It was evinced that PLA/PBS blends had poor results in their foaming capabilities and mechanical performance due to incompatibilities between material phases. However, the addition of DCP greatly increased the blends' performance. PBS enhanced the thermal behavior of the blend, PLA the cell nucleation, and the DCP increased the melt viscosity, crystallization, and material compatibility. As a result, foamed samples of $0.85 \mathrm{~g} / \mathrm{cm}^{3}$ with closed cell structure and higher cell population densities than both neat materials could be obtained. Best results were achieved when $0.1 \mathrm{wt} \%$ of DCP was used, with a good compromise of properties. The blend viscosity and melt strength were increased, its crystallization behavior enhanced, the rigidity of the foamed material was reduced by nearly 2.2 times the elastic modulus of PLA. The relative impact strength was significantly increased from 1.9 to $4.0 \mathrm{~kJ} \cdot \mathrm{cm}^{3} /\left(\mathrm{m}^{2} \cdot \mathrm{g}\right)$. Regarding the morphology, the obtained sample structure presented a narrow cell size distribution and a cell population density of $1.8 \cdot 10^{5}$ cells $/ \mathrm{cm}^{3}$. However, high contents of DCP presented high crosslinking degrees, negatively affecting the foaming capabilities and performance of the blends. In fact, no foamed samples could be obtained when $1 \mathrm{wt} \%$ of DCP was used.

Other chemical and physical modifications, such as the use of fillers, plasticizers, use of different PLA/ PBS ratios and inclusion of new polymers in the blend, among others, are worthy to study in future works in order to further enhance the mechanical performance of PLA/PBS/DCP foams. For example, a PLA or PBS based CFA is suggested to improve the final blend compatibility.

\section{Acknowledgements}

The authors gratefully acknowledged the technical and financial support of the following organizations and companies: EAFIT University from Colombia, Ruta N, Fraunhofer Gesellschaft and all the technical and scientific staff members of the ICIPC who helped with many an inspiring discussion as well as with obtaining the results.

\section{References}

[1] Nair N. R., Sekhar V. C., Nampoothiri K. M., Pandey A.: Biodegradation of biopolymers. in 'Current developments in biotechnology and bioengineering' (eds.: Pandey A., Negi S., Socco C. R.), Elsevier, Amsterdam, 739-755 (2017).

https://doi.org/10.1016/B978-0-444-63662-1.00032-4

[2] Niaounakis M.: Biopolymers: Processing and products. Elsevier, Amsterdam (2015).

[3] Muthuraj R., Misra M., Mohanty A. K.: Biodegradable compatibilized polymer blends for packaging applications: A literature review. Journal of Applied Polymer Science, 135, 45726/1-45726/1 (2018).

https://doi.org/10.1002/app.45726

[4] Nofar M., Sacligil D., Carreau P. J., Kamal M. R., Heuzey M-C.: Poly(lactic acid) blends: Processing, properties and applications. International Journal of Biological Macromolecules, 125, 307-360 (2019).

https://doi.org/10.1016/j.ijbiomac.2018.12.002

[5] Deng Y., Thomas N. L.: Blending poly(butylene succinate) with poly(lactic acid): Ductility and phase inversion effects. European Polymer Journal, 71, 534-546 (2015).

https://doi.org/10.1016/j.eurpolymj.2015.08.029

[6] Plastics - The facts. PlasticsEurope, Belgium (2018).

[7] Julien J. M., Quantin J-C., Bénézet J-C., Bergeret A., Lacrampe M. F., Krawczak P.: Chemical foaming extrusion of poly(lactic acid) with chain-extenders: Physical and morphological characterizations. European Polymer Journal, 67, 40-49 (2015).

https://doi.org/10.1016/j.eurpolymj.2015.03.011

[8] Litauszki K., Kmetty Á.: Development and characterization of innovative biopolymer foams. IOP Conference Series: Materials Science and Engineering, 426, 012031/1-012031/9 (2018).

https://doi.org/10.1088/1757-899X/426/1/012031

[9] Campuzano J.: Physical foaming using high pressure gas saturation for biopolymer applications. in 'Spe Antec Coference, Orlando, Florida' Vol 607, 1-5 (2018).

[10] Nofar M., Park C. B.: Poly (lactic acid) foaming. Progress in Polymer Science, 39, 1721-1741 (2014). https://doi.org/10.1016/j.progpolymsci.2014.04.001

[11] Boonprasertpoh A., Pentrakoon D., Junkasem J.: Effect of crosslinking agent and branching agent on morphological and physical properties of poly(butylene succinate) foams. Cellular Polymers, 36, 333-354 (2017). https://doi.org/10.1177/026248931703600603

[12] Chaiwutthinan P., Leejarkpai T., Kashima D. P., Chuayjuljit S.: Poly(lactic acid)/poly(butylene succinate) blends filled with epoxy functionalised polymeric chain extender. Advanced Materials Research, 664, 644-648 (2013).

https://doi.org/10.4028/www.scientific.net/AMR.664.644 
[13] Ren J., Fu H., Ren T., Yuan W.: Preparation, characterization and properties of binary and ternary blends with thermoplastic starch, poly(lactic acid) and poly(butylene adipate- $c o$-terephthalate). Carbohydrate Polymers, 77, 576-582 (2009). https://doi.org/10.1016/j.carbpol.2009.01.024

[14] Todo M., Park S-D., Takayama T., Arakawa K.: Fracture micromechanisms of bioabsorbable PLLA/PCL polymer blends. Engineering Fracture Mechanics, 74, 1872-1883 (2007).

https://doi.org/10.1016/j.engfracmech.2006.05.021

[15] Arrieta M. P., López J., Hernández A., Rayón E.: Ternary PLA-PHB-limonene blends intended for biodegradable food packaging applications. European Polymer Journal, 50, 255-270 (2014).

https://doi.org/10.1016/j.eurpolymj.2013.11.009

[16] Imre B., Pukánszky B.: Compatibilization in bio-based and biodegradable polymer blends. European Polymer Journal, 49, 1215-1233 (2013). https://doi.org/10.1016/j.eurpolymj.2013.01.019

[17] Ji D., Liu Z., Lan X., Wu F., Xie B., Yang M.: Morphology, rheology, crystallization behavior, and mechanical properties of poly(lactic acid)/poly(butylene succinate)/ dicumyl peroxide reactive blends. Journal of Applied Polymer Science, 131, 39580/1-39580/8 (2014). https://doi.org/10.1002/app.39580

[18] Wang R., Wang S., Zhang Y., Wan C., Ma P.: Toughening modification of PLLA/PBS blends via in situ compatibilization. Polymer Engineering and Science, 49, 26-33 (2009).

https://doi.org/10.1002/pen.21210

[19] Ludwiczak J., Kozlowski M.: Foaming of polylactide in the presence of chain extender. Journal of Polymers and the Environment, 23, 137-142 (2015). https://doi.org/10.1007/s10924-014-0658-7

[20] Bocz K., Tábi T., Vadas D., Sauceau M., Fages J., Marosi Gy.: Characterisation of natural fibre reinforced PLA foams prepared by supercritical $\mathrm{CO}_{2}$ assisted extrusion. Express Polymer Letters, 10, 771-779 (2016). https://doi.org/10.3144/expresspolymlett.2016.71
[21] Göttermann S., Standau T., Weinmann S., Altstädt V., Bonten C.: Effect of chemical modification on the thermal and rheological properties of polylactide. Polymer Engineering and Science, 47, 21-25 (2017). https://doi.org/10.1002/pen.24505

[22] Standau T., Murillo Castellón S., Delavoie A., Bonten C., Altstädt V.: Effects of chemical modifications on the rheological and the expansion behavior of polylactide (PLA) in foam extrusion. e-Polymers, 19, 297-304 (2019). https://doi.org/10.1515/epoly-2019-0030

[23] Feng Z., Luo Y., Hong Y., Wu J., Zhu J., Li H., Qi R., Jiang P.: Preparation of enhanced poly(butylene succinate) foams. Polymer Engineering and Science, 56, 1275-1282 (2016). https://doi.org/10.1002/pen.24362

[24] Kmetty Á., Litauszki K., Réti D.: Characterization of different chemical blowing agents and their applicability to produce poly(lactic acid) foams by extrusion. Applied Sciences, 8, 1960/1-1960/17 (2018). https://doi.org/10.3390/app8101960

[25] Reyes-Labarta J. A., Marcilla A.: Kinetic study of the decompositions involved in the thermal degradation of commercial azodicarbonamide. Journal of Applied Polymer Science, 107, 339-346 (2008). https://doi.org/10.1002/app.26922

[26] Jin F-L., Zhao M., Park M., Park S-J.: Recent trends of foaming in polymer processing: A review. Polymers, 11, 953/1-953/23 (2019). https://doi.org/10.3390/polym11060953

[27] Winter H. H.: Three views of viscoelasticity for CoxMerz materials. Rheologica Acta, 48, 241-243 (2009). https://doi.org/10.1007/s00397-008-0329-5

[28] Coccorullo I., Di Maio L., Montesano S., Incarnato L.: Theoretical and experimental study of foaming process with chain extended recycled PET. Express Polymer Letters, 3, 84-96 (2009). https://doi.org/10.3144/expresspolymlett.2009.12 